\title{
InVisible Culture
}

\section{Introduction / Issue 32: Rest and the Rest: The Aesthetics of Idleness}

Jean Ma

Published on: Apr 25, 2021

DOI: $10.47761 / 494 a 02 f 6.08 \mathrm{ae} 28 \mathrm{cb}$

License: Creative Commons Attribution 4.0 International License(CC-BY 4.0). 


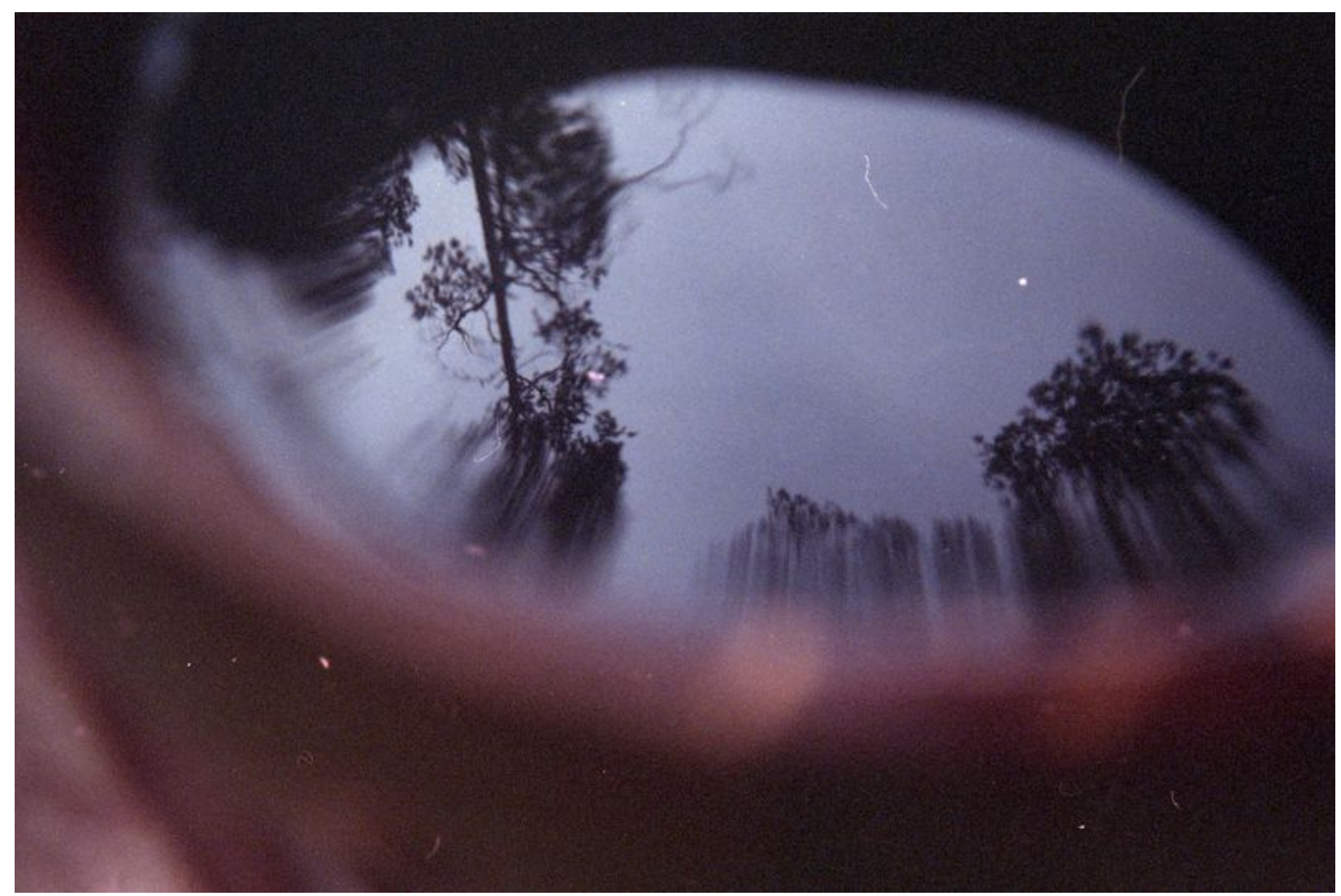

Artwork by contributor Nina Luostarinen.

For Issue 30, the editorial board of InVisible Culture is honored to present a special introduction by Dr. Jean Ma. Also in this issue: "The Somnophile's Guide to Cinema: An Interview with Jean Ma."

"Satan finds some mischief still for idle hands to do," the old saying goes, or in another version of the phrase, "the devil finds work for idle hands." The adage makes an equation between a lack of occupation and laxity of moral character: to abstain from the exertions of meaningful activity is to avail oneself to the devil's enjoinment. Evil rushes into the void of vacant time. Then again, perhaps the devil is idleness itself, a condition whose conceptualization descends from acedia (in Greek, lack of care) and sloth. For the ascetic monks of the fourth century, acedia was a dreaded demonindeed, "the most oppressive of all the demons," according to Evagrius of Ponticus. 1 Often creeping in from the hours of late morning to early afternoon and exerting a 
drag on the passage of time, even seeming to slow the journey of the sun in the sky, this noonday demon would distract even the most devoted from their contemplation and labors. In the thrall of its influence and its deceleration of time, the monk would find himself taken by "a dislike for the place and for his state of life itself, for manual labour," no longer content with the fulfillment of his duty. Mingled with this antipathy are forbidden cravings-for "other places," where he can pursue easier trades and ways of living, and enjoy the company of others. The ascetic's thoughts turn and desires churn as he remembers his former life and catches glimpses of the future in wait. The demon, Evagrius writes, "depicts for him the long course of his lifetime, while bringing the burdens of asceticism before his eyes."

Several centuries later, acedia was translated and recast as sloth, a deadly sin that preserves the association between inoccupation, straying from duty, and wavering in faith. According to Daniel Rosenberg, the linguistic shift from acedia to sloth paved the way by which what was once "a specifically monastic problem" eventually becomes "a general cultural concern." 2 The peculiar structure of feeling and cluster of symptoms to which acedia originally referred fade into the distance, while sloth comes to be understood in terms of a "vague equivalence" with a looser set of terms that include laziness, indolence, drowsiness, apathy, boredom, and ennui. Thinkers like Evagrius were at pains to distinguish acedia from such manifestations of "everyday carelessness," Rosenberg argues. Even if important dimensions are lost in the historical transition from the monastic setting to the secular everyday, however, the demon still lingers. It lodges at the core of the concept and rears its head whenever the hands idle in their labors, as the old sayings remind us.

Indeed the stain of vice sets idleness (along with its close adjuncts indolence and laziness) apart from other inactive and disorganized states of mind like boredom and somnolence, which retain a morally neutral valence even while emerging as pressing culture concerns of their own. In a modern era shaped by the credo of work as both a spiritual calling and utilitarian imperative, idleness remains not only a devil of sorts, but the most oppressive of all the demons. As an idea of evil conjured by capitalist reason, it is tailored to the needs of a new ethic of work as an end in itself. The unquestionable virtue of work is propped upon the pillar of an idle sin that must be exorcised at whatever cost. Thus the charge of idleness raises an alarm that warrants the most extreme and inhumane of countermeasures. As Saidiya Hartman writes, "Panic about idleness, intemperate consumption, and fanciful expression of freedom" have long been mobilized to justify "coercive labor measures and the constriction of liberties." $\underline{3}$ The invocation of idleness as a special predisposition in the discursive 
construction of innate racial differences-as in the myth of the "lazy native"-served to authorize a host of violent techniques for the extraction of labor, from chattel slavery in the Americas to forced cultivation and indenture in the colonies of Asia. The projection of a predilection for vice upon the unengaged body informs the construction of the legal code, as in the vagrancy laws that make a crime of doing and owning nothing. $\underline{4}$ And in the court of popular opinion to the present day, idleness continues to be associated with the depravity of excessive leisure and consumption, of wasteful extravagance and indulgence, as signaled in the phrase "the idle rich."

To the degree that idleness carries a particular stigma, it lies beyond the pale of absolution, unlike its cousins boredom and sleep. As Marina van Zuylen demonstrates, the fascination with boredom as a symptom of modern life-even the key affect of modernity-reveals its ambivalent status. $\underline{5}$ On the one hand, boredom implies inoccupation, a fall into apathy, a surrender to melancholy or depression. But on the other hand, it is precisely by way of this depressing route that one arrives at deeper knowledge, sharpened experience, and even the divine, van Zuylen argues. Tracing a discourse of "restorative boredom" that runs from Pascal to Heidegger to Kracauer, she shows how boredom's inoccupation is transformed into "the only proper occupation." $\underline{6}$ It carves out a pathway that cuts through the trivial diversions of everyday life towards a more profound glimpse into one's condition, holding out a "guarantee of control over one's existence." $\underline{7}$ Considered from this restorative perspective, boredom is not so boring after all. And in our current moment, neither is sleep understood according to what it was previously believed to be, a waste of time and the ultimate extreme of lassitude. For Evagrius, the arrival of the noonday demon was announced by the onset of somnolence. He defines acedia as a slackening of ascesis, untimely drowsiness, revolving sleep"-a definition preserved in the exhortation of Proverbs 6.4 "not to give sleep to the eyes nor drowsiness to the eyelids." $\underline{8}$ But today, it is not excessive sleep, but rather the lack of sleep that gives rise to "ethical deviance," as Matthew Walker argues. Walker, who is the Director of the Center for Human Sleep Science at UC Berkeley, makes a series of startling claims in his bestselling popular science and self-help book of 2017, Why We Sleep: Unlocking the Power of Sleep and Dreams. $\underline{9}$ Walker blames sleep-deprivation, a pervasive condition in the era of around-the-clock work, for a host of ills that include poor job performance, inefficiency, slacking off, and even unscrupulous behaviors such as petty embezzlement. "Under-slept employees are not only less productive, less motivated, less creative, less happy, and lazier, but they are also more unethical," he argues. $\underline{10}$ The charge for the industrious employee is then not to deny sleep to their eyes, but 
instead to manage their hours of restorative rest with a view to maximizing productivity for the optimal benefit of their organization-and increasingly, to do so under the guidance of workplace wellness programs that emphasize sleep hygiene and strategic napping. Like boredom, sleep harmonizes with, instead of contravening, a proper occupation.

But unlike boredom and sleep, idleness is difficult to absorb into a program of restoration. Indeed, the recuperating logics outlined above depend upon the discernment of subtle but crucial distinctions between the depths of ennui and the shallows of idleness, between the midday naps taken by the responsible worker and those taken by the irredeemable slacker. And herein lies the potency of idleness, grasped as that which resists assimilation to productivist values, or which the latter absorb at their own peril. Thus the "hedonist Marxist" Paul Larfargue pledged his faith to those who have "preached idleness," like Jesus in his sermon on the Mount ("Consider the lilies of the field, how they grow: they toil not, neither do they spin: and yet I say unto you that even Solomon in all his glory was not arrayed like one of these"). $\frac{11}{}$ Denouncing the working-class's demand for the right to work in its revolutionary platform, Lafargue invokes "the right to be lazy" and gives this title to his polemical tract. "Shame to the French proletariat!" he writes, for allowing themselves "to be degraded by the religion of work." $\underline{12}$ As Kathi Weeks points out, "One of the most striking elements of the text is Lafargue's rather extravagant refusal to rehabilitate nonwork by recourse to productivist values." $\underline{13}$ Four decades later, Lafargue's call for a new anti-work gospel would be taken up by the philosopher Bertrand Russell in his essay "In Praise of Idleness." $\underline{14}$ Russell similarly declares, "What needs to be preached in modern industrial countries is quite different from what always has been preached." The unquestioned belief in the virtue of work has wrought "immense harm" rather than good, generating a situation of deprivation and "arduous struggle" for some, and comfortable ease for select others. What the greater good requires then is not greater productivity, but rather a redistribution across society of the fruits of labor and delightful leisure. For Russell, idleness is not a vice, but a "right," and more crucially, a right that must be "evenly distributed throughout the community."

When the pillar of sin is toppled, the virtue of work is no longer self-evident. And after the dust of old superstitions has settled, what kinds of new values and imaginaries emerge into visibility? The essays in this special issue take up this question. They engage the theme of idleness as a starting point for a critique of capitalist reason, its legacies and ongoing production of violence (Irene Alcubilla Troughton, Michael 
Krawczyk, Heidi Andrew Restrepo Rhodes). In idleness, they discover a resource for extravagant refusals, strategic disidentifications, and the forging of solidarities among people and with the nonhuman world (Nina Luostarinen, Emily Bock, Paula Vilaplana de Miguel). If idleness is a distraction, it is the distraction we need, a "kind of interruption you desire," as Bock writes in her contribution. $\underline{15}$ Welcome this noonday demon and the vision it brings of the future ahead, along with the "possible otherwise" at the edge of the horizon.

Emily Bock’s essay, “Cultivating_(In)attention, Listening to Noise," is about noise: loud, rhythmic, and extralinguistic. It explores how noise invites a particular mode of listening, a different way of experiencing and inhabiting interruptions of ordinary life. As a sensorial experience, balls have a peculiar sonic landscape that moves from high intensity house music to what could be considered a kind of "white noise," from clear linguistic utterances to a collection of scat like vocal improvisations, from the background to the fore. In attending to the oscillation between moments of aural attention and inattention, we catch a glimpse of how balls provide a temporal grammar that refigures attachments to the future and past, creating a scene in which affects and sensibilities are learned through the practice of listening.

Irene Alcubilla Troughton's article “Cracks of Productivity: The Vitality of the 'flesh' in Danzad Malditos" offers a perspective on the ethics of idleness by analyzing the cracks of productivity, as well as how its failures can offer alternative modes of relating. By means of an analysis of the Spanish theatre play Danzad Malditos, a free adaptation of Sydney Pollack's They Shoot Horses, Don't They?, Troughton develops the concept of the "vitality of the flesh" as a creative intervention into what it means to fail at being productive in contemporary society. Basing her theoretical inquiries on the work of Giorgio Agamben, Jack Halberstam and Maurice Merleau-Ponty, the author traces the concept of "flesh" through its biopolitical, ethical and perceptual strands, respectively, using Danzad Malditos as a case study. She argues that by exposing the flesh of the performers not just as worn-out bodies but as showing a new type of vitality, Danzad Malditos provides a critique of productivity. At the same time, the play 
opens another path for relating to others: in more ethical, posthuman entanglements where that exhausted and unproductive flesh becomes the main connecting point among entities.

Drawing on recent studies in film, economic theory, sociology, and gender, Paula Vilaplana de Miguel's "The House that Ghosts Built (And Mediums Performed)." explores the architectural dimension of haunting, reflecting on the intersections between gender, real estate, and the occult that such spaces articulate. The emergence of Spiritualism in the late nineteenth century situates the Victorian house at the core of its practice. The presence of ghosts is tied to the performance of the (often) female medium during the Spiritualist séance, a spectacle that transforms the parlor into a public stage for the radical performance of political, social, and sexual claims. This first type of haunting differs from the familiar depiction of the haunted house presented through film, literature, and even historical landmarks which serve today as haunted attractions. There is nonetheless a consistency between the historical and fictional representations: the juxtaposition of Victorian dwellings and troubling women. What, I would like to ask, triggers the transition between these two interrelated but discordant understandings of haunting?

“Dolce far niente, Ärjä,," a visual essay created by Nina Luostarinen presents an artbased participatory research project: an emotional mapping photoplay that took place during Ärjä Art Festival in August 2019. By showing 15 examples of 2016 entries gathered during this photo-based intervention into a nature heritage location this contribution discusses the possibilities of reimagining the relationship to a place, representing and communicating the past by creating collective imagery of a location. A significant number of photographs to emerge from the project depicted idleness: resting, gazing the horizon, equipment of sleep in the nature, and just floating in the sweet idleness of doing nothing and being one with the landscape, experiencing the place as a palimpsest of emotional and narrative layers. By enabling site-specific play and eliciting the landscape's ludic and idle aesthetics, the exercise revealed how participants form a sense of attachment to a place.

Apis Mellifera is a short film edited from excerpts from Michał Krawczyk's current work-in-progress In the Natural Apiary. The edited short film merges long takes from the apiary achieved through a specific aesthetical intervention, which he calls the "ecoaesthetics of stillness." Through the adoption of long takes, Michał mediates between the interplay of stillness and motion, capturing the unfolding of events within the apiary. He had to adapt his body movements and positions as to not disrupt the 
flight path of the bees, thus adopting to the terrain and embracing a "response-able" practice of filmmaking, akin to the beekeeper's own practices. Michał turned to both slow cinema and ecocinema to reflect on the slow violence of the mass extinction of non-human species.

Jean Ma is the author of Melancholy Drift: Marking Time in Chinese Cinema (Hong Kong UP, 2010) and Sounding the Modern Woman (Duke UP, 2015). Her editorial work includes the anthology Still Moving: Between Cinema and Photography (Duke UP, 2008), a special issue of the Journal of Chinese Cinemas on sound and music, and a book series at the University of California Press on "Music, Sound, and Media." Her writing has appeared in Grey Room, Camera Obscura, Criticism, Journal of Chinese Cinemas, and Film Quarterly, as well as in numerous edited volumes. She is an Associate Professor in the Department of Art and Art History at Stanford University, where she teaches in the Film and Media Studies Program. 